\title{
Study of bronze repairs by finite element method (FEM) interpretation of the thermographic results
}

\author{
by G. Caruso*, F. Mercuri**, S. Paoloni ${ }^{* *}$, N. Orazi" ${ }^{* *}$, U. Zammit**, \\ C. Cicero**, M. Ferretti*, O. Colacicchi Alessandri***
}

\begin{abstract}
* ITABC -CNR, Area della Ricerca Roma 1 - Montelibretti, Via Salaria Km. 29,300-00015 Monterotondo St. (ROMA), Italia.

** Dipartimento di Ingegneria Industriale, Università di Roma Tor Vergata, via del Politecnico-00133 Roma, Italia.

*** Museo Nazionale Romano-Palazzo Massimo, Largo Villa Peretti 2-00185, Roma, Italia.
\end{abstract}

\begin{abstract}
In this work the finite element method (FEM) is proposed for the interpretation of the thermographic results obtained on ancient bronzes. In particular, mechanical and metallurgic repairs are characterized by analysing the interface between patches and underlying bronze bulks in order to recognize the different kind of repairs operated by the artists. The obtained results are then used as a starting point to improve the knowledge of the bronze manufacturing process.

Finally, this method is used to interpret the thermographic results obtained on some masterpieces of bronze statuary, like the Boxer at Rest, belonging to the Museo Nazionale Romano.
\end{abstract}

\section{Introduction}

In the field of cultural heritage, the non-destructive characterization of the structures and the materials of artworks can be considered a crucial starting point to improve the general knowledge about them and to determine their manufacturing process. In this regard from the artistic and historical point of view, a very interesting case concerns the analysis of the manufacturing process of ancient bronzes which, in the past, were largely produced by means of the indirect lost wax method [1-2]. According to this method, after the casting different repairs can be operated to mend the holes left in the bronze after the casting [3]. On the basis of the nature of the repair, two main categories of repairs can be identified: the mechanical and the metallurgical ones. Mechanical repairs consist of regular patches, wedged into prepared cavities, which are commonly planned and characterized by a regular geometry. On the other hand, metallurgic repairs are cast locally where faults of the original casting occurred or when the bronze geometry does not allow a mechanical intervention [3].

Recently, such kind of features have been successfully studied in a non-destructive way by infrared thermography (IRT) [4]. In particular, a series of qualitative and quantitative thermographic analysis has been performed in order to study the structure of the different kind of patches and then to classify them according to their purpose, a fundamental aspect when trying to verify the main steps of the manufacturing process [5-6].

In this work, the study of the interface between the patch and the underlying bronze bulk is proposed by the finite element method (FEM) [7] interpretation of the thermographic results in order to recognize the repairs typology operated by the artists [8]. In particular, a numerical model is proposed to supply an estimate of some parameters characterizing the different kind of repairs. In fact, once the mass density $\rho$, the specific heat $c$ and the thermal conductivity $k$ have been set, based on the available data in the literature and on direct measurements, the signal time dependence is strongly affected by the interface thermal conductance $G$ characterizing the heat flow between the patch and the bronze bulk through the equation $G \Delta T=Q$, where $\Delta T$ is the temperature difference across the two sides of the interface and $Q$ is the heat flux, which is continuous at the interface. Adiabatic boundary conditions are enforced on the top, bottom and the external lateral surface of the patch-substrate system. In the present case $G$ is assumed equal at all interfaces around the patch. A step like initial temperature increase is imposed at the top surface, due to the flash energy delivery.

In figure 1, three simulation curves, obtained on a specimen comprising a bronze patch of thickness $h=3 \mathrm{~mm}$, bonded on a bronze bulk of thickness $H=5 \mathrm{~mm}$ are shown. The curves represent situations, respectively, with a poor contact (blue line, $G=100 \mathrm{~W} /\left(\mathrm{m}^{2} \mathrm{~K}\right)$, with a fair contact (red line, $G=4000 \mathrm{~W} /\left(\mathrm{m}^{2} \mathrm{~K}\right)$ and with an excellent interface conduct (green line, $G=106 \mathrm{~W} /\left(\mathrm{m}^{2} \mathrm{~K}\right)$. After an initial part of the curves behaving linearly with slope -0.5 in double log plot, the time where this slope change occurs, depends on the top layer thickness $h$. If $G$ was zero, i.e. the top layer is thermally insulated from the substrate, the curve after point $A$ would assume a stationary value. With $G$ values different from zero, a shoulder feature appears were the extension of the region between point $A$ and point $B$ as well as the slope at $B$ would crucially depend on $G$ thus allowing its estimate from the experimental results.

Finally, the obtained results are used to interpret the thermographic data measured on some masterpieces of bronze statuary, like the Boxer at Rest and the Hellenistic Prince, belonging to the collection of the Museo Nazionale Romano. In 
both bronzes several patches have been detected and characterized by infrared thermography on the basis of the above-presented method.

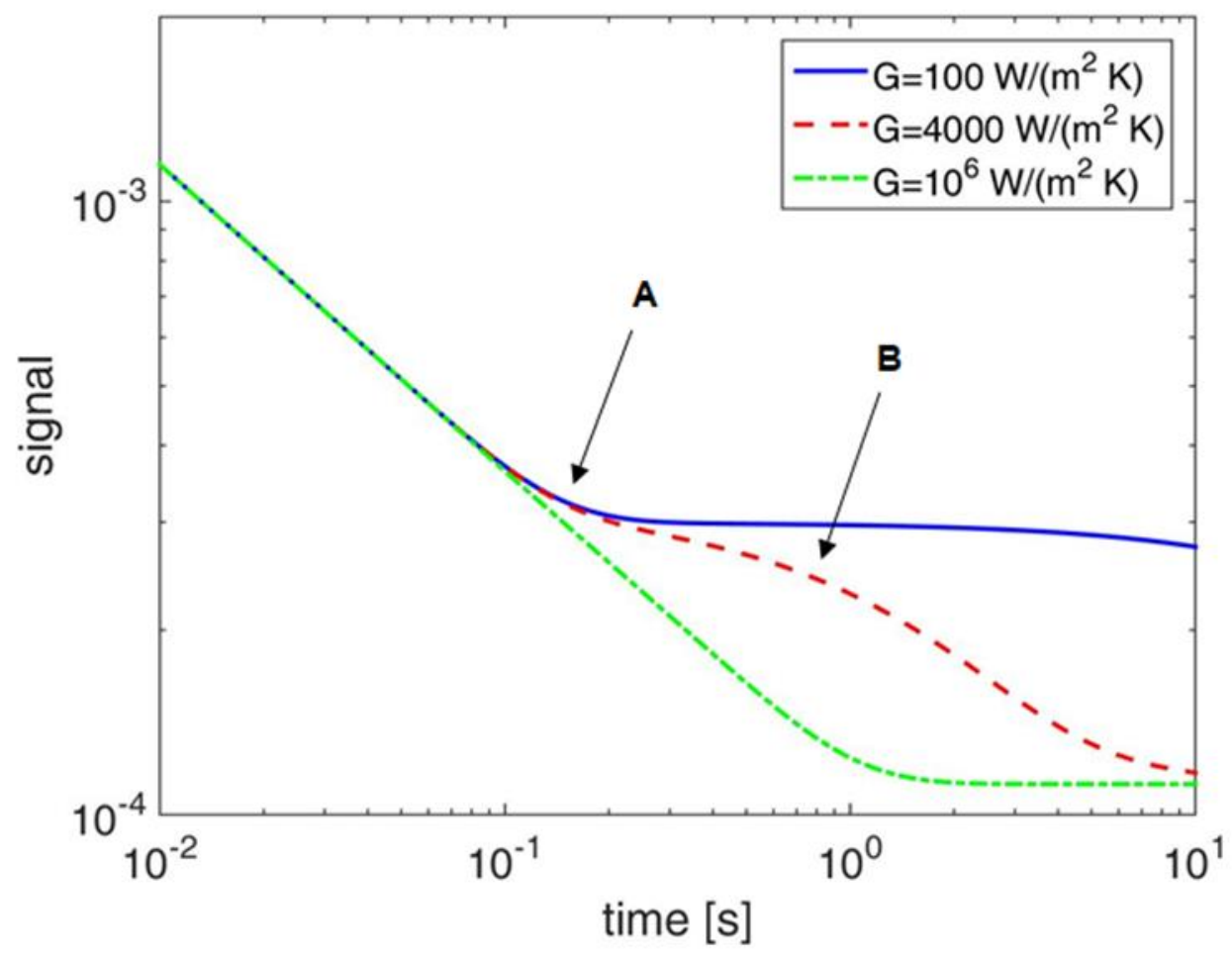

Fig. 1. Simulation curves of a specimen comprising a bronze patch of thickness $H=3 \mathrm{~mm}$, bonded on a bronze bulk of thickness $H=5 \mathrm{~mm}$. The curve represent respectively a patch with a bad contact (blue line, $\mathrm{G}=100 \mathrm{~W} /\left(\mathrm{m}^{2} \mathrm{~K}\right)$ ), a patch with a fair contact (red line, $G=4000 \mathrm{~W} /\left(\mathrm{m}^{2} \mathrm{~K}\right)$ ) and a metallurgic patch (green line, $\mathrm{G}=106 \mathrm{~W} /\left(\mathrm{m}^{2} \mathrm{~K}\right)$.

\section{REFERENCES}

[1] Morigi G. Fusione a cera persa con tecnica indiretta. Bologna: Comune Assessorato alla cultura; 1991.

[2] Fidanza G.B. Le forme del bronzo: ricostruzione della fusione a cera persa con tecnica indiretta in età moderna (da un crocifisso di Gian Lorenzo Bernini ed Ercole Ferrata). Ancona: Fabriano; 2005.

[3] Giuffredi A. Formatura e fonderia, guida ai processi di lavorazione. Florence: Alinea Editrice s.r.l.; 2010.

[4] Orazi N, Mercuri F, Zammit U, Paoloni S, Marinelli M, Giuffredi A, Salerno C.S. Thermographic analysis of bronze sculptures. Stud. Conserv. 2016; 61, 4: 236-244.

[5] Mercuri F, Paoloni S, Orazi N, Cicero C, Zammit U. Pulsed infrared thermography applied to quantitative characterization of the structure and the casting faults of the Capitoline She Wolf. Appl. Phys. A 2017; 123: 317.

[6] Mercuri F, Orazi N, Zammit U, Giuffredi A, Salerno C.S, Cicero C, Paoloni S. The manufacturing process of the Capitoline She Wolf: a thermographic method for the investigation of repairs and casting faults, J. Archaeol. Sci.: Reports 2017; 14: 199-207.

[7] Zienkiewicz O.C, Taylor R.L, Zhu J.Z. The Finite Element Method: Its Basis and Fundamentals. Oxford: Elsevier; 2013.

[8] Mercuri F, Caruso G, Orazi N, Zammit U, Cicero C, Colacicchi Alessandri O, Ferretti M, Paoloni S. Interface thermal conductance characterization by infrared thermography: A tool for the study of insertions in bronze ancient Statuary, Infrared Physics \& Technology 2018; 90: 31-39, 